\title{
APPLYING INDUSTRY 4.0 AND EDUCATION 4.0 TO ENGINEERING EDUCATION
}

\author{
Irina Neaga \\ School of Engineering, University of Wales Trinity St David, Swansea, Wales, United Kingdom \\ Corresponding Author Irina.Neaga@uwtsd.ac.uk
}

\begin{abstract}
This research work-in-progress deals with a holistic analysis of the impacts of Industry 4.0 (I4.0) for engineering education especially for University undergraduate (level 4-6), master (level 7) and PhD related manufacturing, automotive engineering and supply chain management programmes in United Kingdom higher education institutions. This analysis aims at providing support for further consolidated recommendations to enable the development of higher education engineering curriculum for enhancing I4.0 application for smart organisations and industrial companies within the digital supply chains. Also the paper provides an analysis of advancement from digitalisation in engineering education to the implementation of Education 4.0 and related practices of smart labs, and simulation of smart factories leading at the learning factory. A conceptual framework to support the application of big data and learning analytics in the School of Engineering from University of Wales Trinity St David, Swansea, United Kingdom has been identified, discussed and intended to apply in the context of applying learning analytics.
\end{abstract}

Keywords: Industry 4.0 and Education 4.0: Internet-ofThings (IoT): Smart and learning factory: virtual learning environment: learning analytics.

\section{INTRODUCTION}

The Industry 4.0 has been initially called Industrie 4.0 as it was launched during the Hannover Fair in 2011; "furthermore, it was officially announced in 2013 as a German strategic initiative to take a pioneering role in industries which are currently revolutionizing the manufacturing sector" ( $\mathrm{Xu}, \mathrm{Xu}$ and $\mathrm{Li}, 2018: 2941$ ). The industry 4.0 has included several technologies as presented in figure 1. Several recent approaches demonstrate how Industry 4.0 represents the evolution of the Fourth Industrial Revolution, upon which Information and Communication Technologies (ICT) form the infrastructural foundation for tomorrow's innovative industrial technologies and educational environments (Mourtzis et al., 2018; Xu, Xu and Li, 2018). The related roadmap presenting the main technologies supporting the evolution from Industry 1.0 to Industry 4.0 is presented in figure 3. (TSB Forum, 2015; Santos et al., 2017). This technological framework could be used for industrial engineering and management applications facilitated by the digital engineering education systems, tools and virtual learning environments.

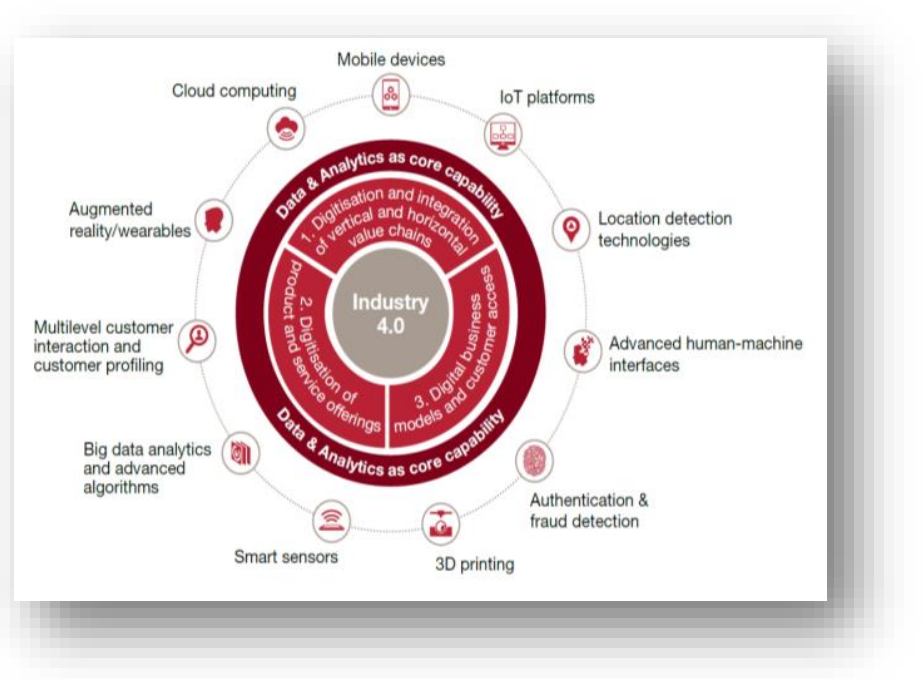

Fig. 1. Industry 4.0 Framework

Education 4.0 is a development based on Industry 4.0 applied concepts and digitalisation of higher education institutions and of teaching and learning practices. Advancement of digital and/or online education supported by an Education 4.0 framework will facilitate the development of skills and building graduates' competences for contemporary industry based on I4.0. According to Mourtzis et al. (2018) technologies such as Internet of Things (IoT), cloud computing, augmented and virtual reality, big data and learning analytics have an important role in engineering and management education, supporting advanced life-long training of the skilled workforce. It has been demonstrated that learning analytics provides insights 
about the teaching practices that could be rapidly adapted (Sclater, Peasgood, and Mullan, 2016).

The paper is organised in distinctive but inter-related sections that are addressing curriculum development to support Industry 4 leading to students and graduates competencies for future rapid employment. Other sections are dedicated to demonstrate the benefits of the application of learning analytics in higher education institutions as complex organisations. Education 4.0 represents the application of Industry 4.0 framework and the associated technologies in education based on the intensive digitalisation.

\subsection{Motivation and Background}

The First Industrial Revolution has began at the end of the eighteenth century and early nineteenth century, which was represented by the introduction of mechanical manufacturing systems utilising water and steam power. The Second Industrial Revolution started in the late nineteenth century, symbolised by mass production using of the electrical energy. The Third Industrial Revolution began in the middle of twentieth century and introduced automation and microelectronic technology into manufacturing. These advances in manufacturing technologies were closely related to ICT. In the Third Industrial Revolution, the advancement of ICT was at the core of every major shift of the manufacturing paradigm. For example, the widespread adoption of computer numerical control (CNC) and industrial robots made flexible manufacturing systems (FMSs) possible; the technologies for computer-aided design (CAD), computeraided manufacturing (CAM) and computer-aided processing planning (CAPP) made computer integrated manufacturing (CIM) possible (Feng, $\mathrm{Li}$, and Cen 2001; $\mathrm{Xu}, \mathrm{Xu}$ and $\mathrm{Li}, 2018$ ).

Industry 4.0 changes the landscape of industry mainly related the following critical aspects (Santos et al., 2017): 1) Improvements in resource efficiency and sustainability of industrial systems, 2) Distributed and responsive industrial systems 3) Human-oriented interfaces and improved work conditions. 4) Development of educational competences based approach and skills. Industry 4.0 aims to increase the digitalization of industrial companies and supply chains, facilitating the communications between people, machines and products, thus enabling real-time access to product, production and supply chain information for participating entities, and the performance of autonomous work processes along the value chains. Thereupon, the European manufacturing sector expects to achieve a growth from $15 \%$ to $20 \%$ by 2030 if it fully implements the digitization of their value chains (TSP Forum, 2015). Also according to Santos et al. (2017) the digitalization of supply chain applying I4.0 can bring positive benefits for sales and operations planning of manufacturers, such as reducing the time to respond to unforeseen events affecting orders (around 300\% improvement), to deliver orders (around 120\% improvements) and time-to-market (approximately $70 \%$ improvement).

Some of the technologies associated with Industry 4.0 are as follows:

- Computer-Aided Design and Manufacturing (CAD/CAM) that support the development of projects and work plans for product and manufacturing using computerized systems;

- Integrated engineering and logistics systems that support systems for information exchange in product development and manufacturing;

- Digital automation infrastructure using sensors that are based on automated systems embedding sensor technology for monitoring through data collection and analysis;

- Flexible manufacturing lines defined as digital automation with sensor technology in manufacturing processes (e.g. radio frequency identification (RFID) in product components and raw material);

- Simulations and analysis of virtual models based on Finite Elements Methods, Computational Fluid Dynamics, etc. for engineering projects and commissioning model-based design of systems, where synthesized models simulates properties of the implemented the model in real world;

- Big data collection and analysis that correlate large amount of data for applications using predictive analytics, data mining, statistical analysis and other tools;

- Digital Product Service Systems incorporating of digital services in products based on IoT platforms, embedded sensors, processors, and software enabling

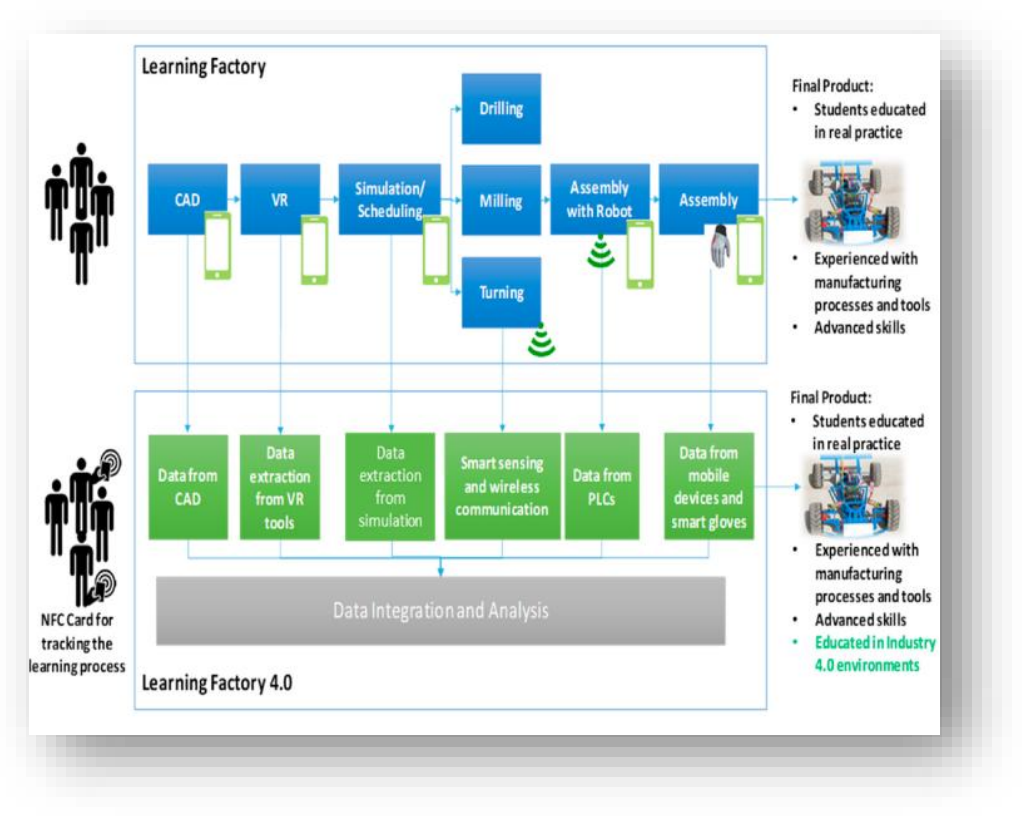

Fig. 2. Implementation of Learning Factory 4.0 
new capabilities;

- Additive manufacturing, fast prototyping or 3D printing;

- Cloud services for products and services.

The engineering education should take these opportunities and quickly respond to the challenges of educating the new generation of engineers, and logistics professionals. Therefore fundamentals of I4.0 and the associated technologies must be taught within the Universities and new curriculum should be developed and applied for new programmes and apprenticeships. Applying Education 4.0 in Engineering Education leads to learning factory 4.0 as shown in figure 2 (Mourtzis et al., 2018).

Extending this approach and the conceptual framework will contribute to the advancement of the traditional teaching to learning using Factory 4.0, integrating CyberPhysical Systems and Industry 4.0 technologies and applying the Education 4.0 framework.

\subsection{Aim and Objectives}

The main aim of this research is to contribute at accelerating the development of Education 4.0 based on a holistic analysis of the impacts of I4.0 and existing Engineering Education strategies and practices regarding digitalisation and generation of large amounts of data.

The related objectives are related to the identification and definition of the:

1. current state of the art of the application of I4.0 and Education 4.0 leading to define Engineering Education 4.0 Framework.

2. benefits of applying Industry 4.0 (I4.0) for Engineering Education Programmes including apprenticeships in United Kingdom.

3. transferable skills and competencies needed by the future engineers to effectively work within an I4.0 industrial environment and related digital supply chains.

4. opportunities and challenges to embed learning analytics within Education 4.0 in higher education organisations.

\section{METHODOLOGICAL APPROACH}

The methodological approach includes performing a systematic review of the literature and using content and thematic analysis (Saunders, Lewis and Thornhill, 2012). The work in progress is based on secondary data analysis of text presented in academic publications and reports. Applying the research case studies (Yin, 2003) methods is based on success of application of learning analytics in higher education in UK Universities (Sclater, Peasgood and Mullan, 2016). This approach could lead to an action research that is a methodology that has become increasingly popular and has been developed in education, specifically at universities and schools directed to influence the best practices. Road mapping could be also applied in order to anticipate the future of the engineering education correlated with industrial needs and skills requirements based on an existing roadmap for I4.0 (Santos et al., 2017)

\section{PRELIMINARY OUTCOMES}

\subsection{Competencies based education framework}

A comparative analysis of the current competencies, knowledge and skills and those required in the future is provided. Ramirez-Mendoza et al. (2018) have proposed the transition from developing skills and acquiring knowledge to competences based education that are presented in figure 3 .
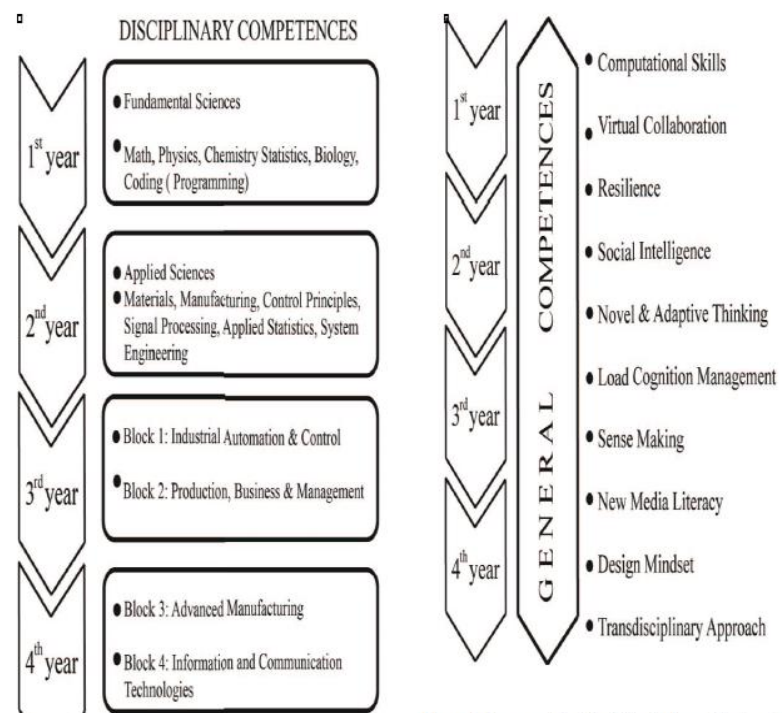

Fig. 3. From Knowledge and Skills to Competenceies

It is also anticipated that final outcomes of the research and the related models will positively influence the collaboration and engagement with industry in the School of Engineering from University of Wales Trinity St David (UWTSD), Swansea, United Kingdom. The Welsh Government addresses the economic development; transport; infrastructure; employment; skills; and research and development, including technology and science providing a set of recommendation as a result of emergence of Industry 4.0 in Wales (National Assembly for Wales Economy, Infrastructure and Skills Committee, 2018).

For a society and economy that enhance the development of 21 st century skills in lifelong learning based on digitalisation of higher education supported by Education 
4.0. 21 st century skills encompass not only technical/engineering and domain-specific knowledge and expertise, but also domain-independent meta-skills such as critical thinking, creativity, communication, and cross cultural collaboration, and moreover dealing with the complexity of future industrial issues of Industry 4.0.

\section{APPLICATION OF LEARNING ANALYTICS}

The outcomes include the definition of the current state of the art of I4.0 and Education 4.0 leading to recommendations to support the I4.0 and increase the benefits of application in industry addressing the shortcomings such as interoperability, information transparency, and trust. The preliminary outcome is the conceptual framework presented in figure 4.

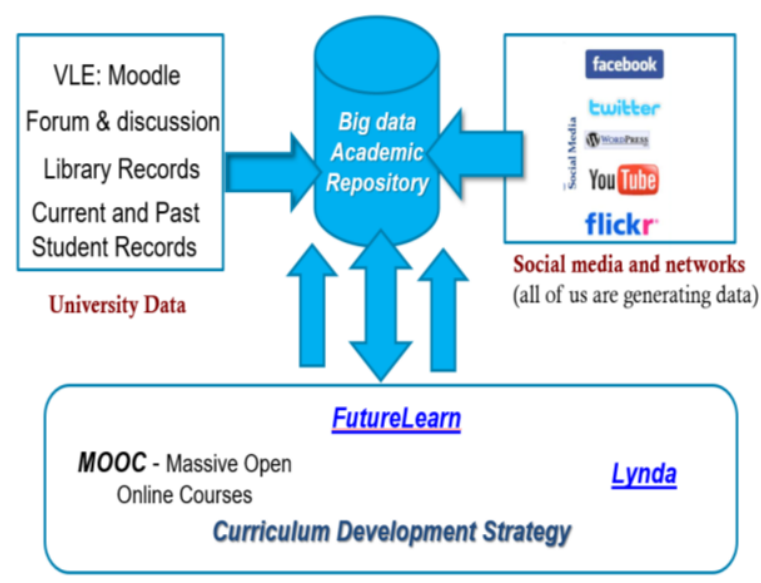

Fig. 4. Conceptual Framework for Learning Analytics

Based on the students' activities, their performance can be predicted applying data, text and web mining techniques (Berman, 2013) such as

- Regression

- Association Rules Discovery

- Classification

- Clustering

- Content and thematic analysis, and

- Running data mining software systems (RapidMiner, XLMiner, Data R)

Predictive Analytics enable prediction of student's behaviour, skills and performance by analysing various traces of their activities while actively interacting with the Virtual Learning Environment and/or using social media.

- Learning analytics (LA) is concerned with the collection, analysis, evaluation and reporting of data about learners and teachers aiming at understanding and optimising learning process, and the related supporting environments in which learning is performing (Daniel, 2015; Sin and Muthu, 2015).

- LA supporting the following aspects and issues in higher education:

- Development and introduction of adaptive learning strategy;

- New pedagogical approaches and development leading at redefining and applying learning styles (Kolb, 1984)

- Quality assurance and improvement;

- Student retention; and

- Overall student experience and engagement.

Academic Analytics (AA) are related to the application of the business intelligence and practices in Higher Education Institutions. Business intelligence is a category of applications and technologies for gathering, storing, analysing, and providing access to data to support organisations to make better business decision (Chatti et al., 2012; West, 2012)

The main challenges of the application of big data and learning analytics are as follows:

- Data integration architecture and systems;

- Selection of suitable data processing, analysing systems and tools;

- Data privacy, especially the new data protection act, and ethical issues of using/exploring student and staff data.

The recommendations for implementing learning analytics are as follows:

- Selection of a suitable LA solution and systems

- Integration of VLE (i.e. Moodle) with other systems (attendance monitoring, feedback tracker, etc.) and related data bases.

- Distinguishing between LA and AA that are oriented towards supporting administrative procedures in higher education institutions.

- Moodle Learning Analytics (i.e. SmartKlass ${ }^{\mathrm{TM}}$ ) should be included as a component of the Moodle VLE to empower teachers/lecturers to manage the learning journeys of their learners.

- Institutional implication and agreements considering specific policies and regulations.

Extending this conceptual framework will further support the implementation of Education 4.0 that is characterised by teachers and trainers using Industry 4.0 technologies (i.e. IoT, RFID) to involve the aspiring engineers and long life learners in real world simulations that increase the perception of the studied material. Additionally, teaching factories 4.0 will serve as an introduction for the aspiring engineers to the newly developed and implemented technologies, through hands on training and workshops 
that call the participants to utilize these technologies as a mean that will improve the quality and the effectiveness of their tasks, potentially unlocking new capabilities. The implementation of these technologies in the teaching laboratories will also boost their integration in a real industrial environment as the new engineers that have familiarized themselves with the true potential and the capabilities provided by I4.0.

\section{CONCLUSIONS AND RECOMMENDATIONS}

The increasingly digitalisation offers great opportunities for Industry 4.0 (I4.0) leading to the generation of new teaching and learning possibilities in the higher education institutions. This has enabled to move forward rapidly as a global society in many respects, but has also led us to complex, diverse and interdisciplinary challenges that affect all areas of knowledge In order to meet major challenges.

The concept of I4.0 together with Education 4.0 bring significant innovation for industry, schools and universities. In order to adequately and timely respond to the need of equipping students with suitable qualification, skills and competencies the education institutions should adapt and the effects of the related changes will be significant, and required to be carefully developed and implemented. The current significant issues of qualified people, made changes in engineering education that will be an important step in raising the standard of engineering education programmes also adopting Education 4.0.

Therefore engineering education should develop and address the following aspects:

- Interdisciplinary educational programmes holistically teaching science, engineering and business courses / modules also providing rapid / real-time innovation of the programmes, and modules in partnerships with industry.

- Adaptive learning environment and associated strategies of rapid adoption.

The recommendations should be based on the interaction between industry experts, academics, and managers in higher education and IT developers of virtual learning environments.

From the technological perspective of I4.0 the following features should be addressed:

- Interoperability of the systems that represents the ability of machines, devices, sensors and people to connect and communicate among each other and on the Internet of things (IoT), as well as on other internet (global) connections and environments.

- Informational transparency and connectivity that is the features of information systems to create virtual copies of the physical world (various simplified, clear models) by connecting large databases and various sensor systems.

- Information trust and relevance that are crucial for information sharing and exchange.

\subsection{Further Work}

The development and adoption of Industry 4.0 and Education 4.0 require further research, and practical applications and the main issues are briefly presented below:

- Developing a comprehensive framework for Engineering Education 4.0 in the School of Engineering from UWTSD.

- Engagement with relevant industry and research institutes in UK and abroad in the context of Industry 4.0 as well as with logistics professional communities in Wales leading to increase impact and collaboration.

- Analysis of the challenges and opportunities of applying the I4.0 for the whole logistics chains.

- Identification of the required competencies of future logistics professionals as well as the identification of the existing gaps in the educational programmes and in the related curriculum in the School of Engineering from UWTSD.

- Definition of the requirements for a new curriculum for Industry 4.0 applying Education 4.0 to logistics and apprenticeships programmes in the School of Engineering from UWTSD.

- Comparatively analysis the research and practices in the higher education institutions in different countries such as UK, Ireland versus Canada.

\section{Acknowledgements}

I acknowledge that this research and participation within Canadian Engineering Education Association (CEEAACEG19) Conference are financially supported by the Seed-Corn funding awarded by UK Canada Foundation, London, United Kingdom.

\section{References}

1. Berman, J.J. (2013) Principles of Big Data: Preparing, Sharing, and Analyzing Complex Information, Morgan Kaufmann Publishers.

2. Chatti, M.A., Dyckhoff, A.L., Schroeder, U. and Thüs, H. (2012) Learning analytics: a review of the state of the art and future challenges', International Journal of Technology Enhanced Learning.

3. Daniel B. (2015). Big data and analytics in higher education: opportunities and challenges. Br. J. Educ. Technol. 46, 904-920. 
4. Eichinger, P., Hofig, B., and Richter, C. (2017) Education 4.0 for Mechatronics - Agile and Smart, IEEE, 2017.

5. Eckroth, J. (2015) Towards a Cross-Disciplinary Pedagogy for Big Data, ACM, 2015.

6. Feng, S., L. Li, and L. Cen. (2001) An Object-oriented Intelligent Design Tool to Aid the Design of Manufacturing Systems. Knowledge-Based Systems 14 (5-6): 225-232.

7. Hoareau McGrath, C., Guerin, B., Harte, E., Frearson, M., and Manville, C. (2015) Learning gain in Higher Education, Rand Europe Report, 2015.

8. Kolb D. A. (1984) Experiential learning: Experience as the source of learning and development, New Jersey: Prentice-Hall.

9. Mourtzis, D., Vlachou, E., Dimitrakopoulos, G., Zogopoulos, V. (2018) Cyber- Physical Systems and Education 4.0 -The Teaching Factory 4.0 Concept, Procedia Manufacturing, Volume 23, pp. 129-134, Elsevier Publishers Ltd.

10. National Assembly for Wales Economy, Infrastructure and Skills Committee (2018) Industry 4.0 - the future of Wales, 2018.

11. Ramirez-Mendoza, R. A., Morales-Menendez, R., Iqbal, H., and Parra-Saldivar, R. Engineering Education 4.0. (2018) IEEE Global Engineering Education Conference 2018, IEEE, pp. 1273-1282

12. Santos, C., Mehrsau, A., Barros, A.C., Araujo, M., and Ares, E. (2017) Towards Industry 4.0: an overview of European strategic roadmaps, Manufacturing Engineering Society International Conference 2017.

13. Saunders, M., Lewis, P. and Thornhill, A. (2012) Research Methods for Business Students. Pearson Education Ltd., Harlow.

14. Schrauf, S. and Berttram, P. Industry 4.0 How digitization makes the supply chain more efficient, agile, and customer-focused, PWC Strategy and Analysis Report, N.D.

15. Sclater, N., Peasgood, A., Mullan, J. (2016) Learning Analytics in Higher Education A review of UK and international practice, Full report, 2016.

16. Sin, K. and Muthu, L. (2015) Application of Big Data in Education Data Mining and Learning Analytics - A Literature Review, ICTACT Journal on Soft Computing, Special Issue on Models for Big Data, 5/04, pp. 1035-1049.

17. T.S.P. Forum (2015) Digital transformation of European Industry and Enterprises: a report of the Strategic Policy Forum on Digital Entrepreneurship, Brussels, 2015.

18. West, D. (2012) Big Data for Education: Data Mining, Data Analytics, and Web Dashboards, Report, 2012.

19. Xu, L. D., Xu, E.L., and Li, L. (2018) Industry 4.0: state of the art and future trends, International Journal of Production Research, 56:8, 2941-2962.

20. Yin, R.K. (2003) Case Study Research: Design and Methods, Sage. Thousand Oaks, California. 